\title{
A NOVEL DYNAMIC KNOWLEDGE EXTRACTION METHOD IN COOPERATIVE MULTIPLE ROBOT SYSTEM USING ROUGH SET
}

Hua Xu and Peifa Jia

State Key Laboratory of Intelligent Technology and Systems, Tsinghua University, Beijing, I00084, P. R. China

Abstract: Dynamic knowledge extraction is one of the critical problems in dynamic systems especially in cooperative multiple robot systems (CMRS).The knowledge may be fuzzy, because the information from dynamic environments is incomplete and uncertain. So it is difficult for traditional methods to extract dynamic knowledge effectively. According to the dynamic knowledge extraction requirements in CMRS, this paper proposes a novel dynamic knowledge extraction method in CMRS on the base of KANG's rough set based rules generation method. It has been demonstrated effective in our CMRS.

Key words: Rough sets, Fuzzy sets, Robotics, Knowledge extraction

\section{INTRODUCTION}

In cooperative multiple robot systems (CMRS), dynamic knowledge extraction is one of the critical problems in dispatching robots for cooperation requirements. The scheduling is conducted by the decision making modules distributed in every robot. According to the environment information, system states and task aims, the decision making module dispatches robots periodically and effectively. However, under different dynamic environments, the knowledge about the environments and tasks is various. At the instance of decision making, dynamic production rules 
generation is required for achieving the dynamic knowledge. That is to say, dynamic knowledge needs to be extracted. Then the extracted dynamic knowledge can be used in the decision making module and the system schedule can be conducted. On the other hand, the knowledge of dynamic environments may be incomplete or uncertain. So the knowledge may be fuzzy and the corresponding inference may be fuzzy reasoning. Above all, it needs a new method to extract dynamic knowledge in CMRS.

Compared with existing methods [6-9], the rough set (RS) theory $[1,2]$ has been proved to be a useful mathematical tool for the analysis of vague description of objects. In order to analyze vague information and get optimal fuzzy production rules, KANG, etc al [3], propose a rules generation method on the base of fuzzy sets (FS) $[4,5]$ and RS $[1,2]$.

This paper proposes a dynamic knowledge extraction method on the base of KANG's RS method. KANG's rules generation method [3] is used to generate dynamic knowledge of CMRS from the practical decision data. The forms of the extracted dynamic knowledge are certain production rules or fuzzy ones

This paper is organized as the following. In section 2, the preliminary notions are quickly reviewed. Section 3 illustrates the decision making subsystem in our CMRS. Then in section 4 , the rules generation of the decision making system is discussed. Finally, the conclusion and future work is summarized in section 5 .

\section{PRELIMINARY NOTIONS OF FS AND RS}

\section{$2.1 \quad$ FS}

In set theory [4], crisp sets are characterized by a Boolean membership function: an element $x$ of the universe of discourse $U$ (say, an interval of real numbers) is either a member of the set or it is not. FS [4], [5] are characterized by a continuous membership function $\mu(x)$ which maps $x$ to a "membership degree" taking values in the interval $[0,1]$.

Definition 2.1: Let $\boldsymbol{U}$ be a set called universe and let $\boldsymbol{A}$ be a fuzzy subset of $U$. For any member $(X)$ of $U$, there exists a mapping function: $X \rightarrow \mu_{A}(X)$, where $X \in U$ and $\mu_{A}(X) \in[0,1] . \mu_{A}(X)$ is called the member function of $\mathrm{A}$ and is continuous on the interval $[0,1]$.

Definition 2.2: For the fuzzy subset $A$, if $\mu_{A}(X) \in\{0,1\}$, then the subset is a common subset. $\square$ 
Definition 2.3: Let $\boldsymbol{F}(\boldsymbol{U})$ be the set of all the fuzzy subsets of $\boldsymbol{U}$ and let $\boldsymbol{P}(\boldsymbol{U})$ be the set of all the subsets of $\boldsymbol{U}$. They satisfies the following proposition: $\boldsymbol{F}(\boldsymbol{U}) \supset \boldsymbol{P}(\boldsymbol{U})$.

Definition 2.4: If $\boldsymbol{A} \subseteq \boldsymbol{F}(\boldsymbol{U})$, then $\boldsymbol{A}$ is a proper fuzzy set of $\boldsymbol{U}$ and there exists a member $\mathrm{x}_{0}$ which satisfies $\mathrm{x}_{0} \in \boldsymbol{A}$ and $\boldsymbol{\mu}_{A}\left(\boldsymbol{x}_{0}\right) \subseteq\{0,1\}$.

Definition 2.5: If the number of fuzzy sets in $\boldsymbol{U}$ is $\boldsymbol{m}$ and these fuzzy subsets represent as $\boldsymbol{A} \boldsymbol{I}, \boldsymbol{A 2}, \ldots$ and $\boldsymbol{A m}$, then

$$
\mu_{\mathrm{A} 1}(\mathrm{X})+\mu_{\mathrm{A} 2}(\mathrm{X})+\ldots+\mu_{\mathrm{Am}}(\mathrm{X})=\mathbf{1}
$$

The nature of FS makes it possible to define partially overlapping classes, thus making it possible a gradual classification of elements in the universe of discourse. By contrast, a model based on crisp sets (intervals) shows abrupt changes when the real value falls in the close interval, due to noise. Imperfect learning and adaptation may affect the quality of the resulting model, and the intrinsic robustness of a fuzzy model plays an important role to smooth this effect.

\subsection{RS}

In RS [1], [2], a rough set can be replaced by two precise sets. One is the lower approximation, while the other is the upper one. The difference between these two approximations is the boundary region (indiscernible region) of the rough set.

Suppose $\boldsymbol{U}$ is a non-empty set as a universe (feature space) and $\boldsymbol{R}$ is an equivalence relation defined by the input features in $U$. According to the equivalence relation $\boldsymbol{R}$, the set $\boldsymbol{U}$ can be partitioned into several basic equivalence classes which do not overlap with each other. Suppose $\mathbf{e}$ is an object of $\mathbf{U}$. Then [e$]_{\mathbf{R}}$ represents a set (an equivalence class) consisting of all the objects which can not be differentiated by the relation $\boldsymbol{R}$. For any subset $\boldsymbol{X}$ of $\boldsymbol{U}$, the lower approximation $\boldsymbol{R} *(\boldsymbol{X})$ and the upper approximation $\boldsymbol{R}^{*}(\boldsymbol{X})$ of $\boldsymbol{X}$ by the relation $\boldsymbol{R}$ are defined by:

$$
\begin{gathered}
R^{*}(X)=\left\{\mathrm{e} \in U:[\mathrm{e}]_{\mathrm{R}} \subseteq \mathrm{X}\right\} \\
R^{*}(x)=\left\{\mathrm{e} \in U:[\mathrm{e}]_{R} \cap X \neq \varnothing\right\}
\end{gathered}
$$

The crisp set $\boldsymbol{R}^{*}(\boldsymbol{X})$ consists of all the objects which surely belong to the set $\boldsymbol{X}$ according to the knowledge provided by $\boldsymbol{R}$. The set $\boldsymbol{R} *(\boldsymbol{X})$ is the union of all the equivalence classes $[\mathbf{e}]_{\mathrm{R}}$ whose intersection with the set $\boldsymbol{X}$ is nonempty, that is, $R^{*}(X)$ consists of all objects possibly belonging to the set $\boldsymbol{X}$ based on the knowledge given by $\boldsymbol{R}$. The boundary region of $\boldsymbol{X}$ by $\boldsymbol{R}$ is defined by: 


$$
B N_{R}(x)=R^{*}(x)-R_{*}(x)
$$

If $B N_{R}(X)$ is empty, the set $\boldsymbol{X}$ is crisp by $R$; otherwise $\boldsymbol{X}$ is a rough set by $\boldsymbol{R}$. $B N_{R}(X)$ contains all the objects which are not classifiable to the set $X$ based on the knowledge given by $\boldsymbol{R}$ in $\boldsymbol{U}$. The basic concept for lower and upper approximations of a rough set is illustrated in Fig. 1

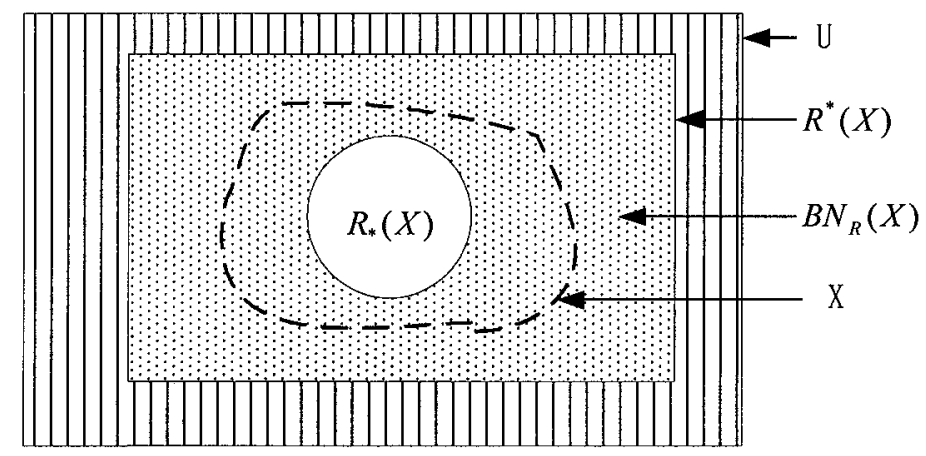

Figure 1 Lower Approximation and Upper Approximation and Boundary Region of A Rough Set $X$

\subsection{The Rules Generation Method on the Base of FS and RS}

On the base of fuzzy set $[4,5]$ and RS theory, KANG [3] presents a rule generation method, which has been discussed in detail in Ref [3]. Its main ideas are reviewed in the following. Some necessary concepts are discussed beforehand.

Definition 2.6: The fuzzy equivalence class $\boldsymbol{R}(\mathrm{k})$ on the universal $\boldsymbol{U}$ is defined as $\boldsymbol{R}(\mathrm{k})=\mathrm{U} / \mathrm{ind}^{*}(\boldsymbol{R})$, where $\operatorname{ind}(\boldsymbol{R})$ is the equivalence relation set on the universal $\boldsymbol{U}$.

Definition 2.7: The fuzzy lower approximation $R_{*}(X)$ is defined as:

$$
\mathrm{R}_{*}(\mathrm{X})=\left\{\left(\mathrm{R}_{\mathrm{k}}(\mathrm{x}), \mu_{\mathrm{Rk}}(\mathrm{X})\right)\left|\mathrm{x} \in \mathrm{U}, \mathrm{R}_{\mathrm{k}}(\mathrm{x}) \subseteq \mathrm{X}, 1 \leq \mathrm{k} \leq\right| \mathrm{R}(\mathrm{X}) \mid\right\}
$$

where $\mu_{\mathrm{Rk}}(\mathrm{x})$ is the member function.

Definition 2.8: The fuzzy upper approximation $\mathrm{R}^{*}(\mathrm{X})$ is defined as:

$$
\mathrm{R}^{*}(\mathrm{X})=\left\{\left(\mathrm{R}_{\mathrm{k}}(\mathrm{x}), \mu_{\mathrm{Rk}}(\mathrm{x})\right)\left|\mathrm{x} \in \mathrm{U}, \mathrm{R}_{\mathrm{k}}(\mathrm{x}) \cap \mathrm{X} \neq \varnothing, 1 \leq \mathrm{k} \leq \mathrm{R}(\mathrm{X})\right|\right\}
$$

where $\mu_{\mathrm{Rk}}(\mathrm{x})$ is the member function.

On the base of FS and RS theory, the KANG's rules generation method is just like the following:

1) Suppose the discussion object set is $U$ ( $i=1$ to $m$ ). The conditional property set is $A(j=1$ to $n)$. The decision property set is $C$. 
2) Decide the member function and language variable (the number of fuzzy intervals) of every conditional property.

3) Depict the member function result figure of the language variable of every conditional property.

4) for $\mathrm{i}=1$ to $\mathrm{m}$

$$
\text { for } j=1 \text { to } n
$$

Transform the conditional property values like the following:

$$
\frac{f_{j 1}^{i}}{R_{j 1}}+\frac{f_{j 2}^{i}}{R_{j 2}}+\cdots+\frac{f_{j l}^{i}}{R_{j l}}
$$

where $R_{\mathrm{jk}}$ is the $\mathrm{k}^{\text {th }}$ fuzzy interval of the conditional property $\mathrm{A}_{\mathrm{j}} \cdot f_{\mathrm{jk}}{ }^{i}$ is the member function value of the object $U^{i}$ on the fuzzy interval $R_{j k}{ }^{i} . l=\left|A_{j}\right|$ is the number of language variable of the conditional property $A_{j}$.

5) Transform the original data table to the decision table with member function values. And calculate the fuzzy equivalence matrix.

6) for $i=1$ to $m$

$$
\begin{aligned}
& \text { for } \mathrm{j}=1 \text { to } n \\
& \begin{aligned}
\text { Set } \mathrm{f}_{\mathrm{jk}}{ }^{i}=\max \left(\mathrm{f}_{\mathrm{j} 1}{ }^{\mathrm{i}}, \ldots, \mathrm{f}_{\mathrm{jl}}{ }^{\mathrm{i}}\right), \text { where } 1 \leq \mathrm{k} \leq l \\
\mathrm{R}_{\mathrm{j}}
\end{aligned}=\mathrm{R}_{\mathrm{jk}}
\end{aligned}
$$

Then the new decision table can be got.

7) Simplify the new decision table using the RS simplifying algorithm, then the reduction rules can be got.

8) The uncertain rule table can be got, which is made up of the incompatible decision and the decision conflicted with the incompatible decision.

9) List the equivalence class of conditional properties in the uncertain rule table. According to its fuzzy equivalence class, the fuzzy equivalence class $A^{\prime}$ ( $k$ ) can be got.

10) Calculate the $A^{\prime}{ }^{*}(k)$.

11) Suppose

$$
\mathrm{D}_{\mathrm{p}}=\mathrm{A}^{\prime}{ }^{*}(\mathrm{C}) \cap(\mathrm{U} / \mathrm{ind}(\mathrm{C}))
$$

where $1 \leq \mathrm{p} \leq\left|\mathrm{A}^{\prime}{ }^{*}(\mathrm{k})\right|$.

The selection function of $D_{p}{ }^{d}$ is defined as the following:

$$
F\left(D_{p}^{d}\right)=\sum_{k=1}^{\left|D_{p}^{d}\right|} \frac{\min \left(f_{j}^{i^{*}}\right)}{\sum_{j=1}^{n} f_{j}^{i^{*}}} \times \frac{D_{p}^{d}}{\mid U / \text { ind }^{*}(C) \mid}
$$

where $1 \leq \mathrm{d} \leq\left|D_{p}{ }^{d}\right| \cdot f_{j}^{\mathrm{i}^{*}}$ is the fuzzy interval value of $\mathrm{A}^{\prime}(\mathrm{k}) . \mid \mathrm{U} /$ ind $^{*}(\mathrm{C}) \mid$ is the umber of decision equivalence class of $D_{p}{ }^{d k}$. 
12) Select the maximum $A^{\prime}$ " $(C)$ in $F\left(D_{p}\right)$ as the final decision, where 1 $\leq \mathrm{p} \leq\left|\mathrm{A}^{\prime *}(\mathrm{C})\right|$.

13) Combine the results in step 7) with those in step 12), the final decision rules can be got.

\section{THE DECISION MAKING IN OUR CMRS}

In CMRS, decision making is one of the important parts. However, this kind of robot systems always works in dynamic environments. The dynamic knowledge can not be summarized accurately beforehand. Usually it is fuzzy, incomplete or uncertain. What's more, decision making rules in dynamic environments stem from practical data in dynamic states. In order to generate the decision making rules from practices, the FS and RS based rules generation method [20] is used to get decision rules.

Our cooperative multiple robot system is a kind of distributed cooperative multiple robot system. It has a two-level system structure in every robot subsystem. The higher level is decision making layer. The lower level is control layer. According to the robot work state, velocity, movement direction and aim distance, decisions of every robot are made respectively, when a new task needs to be performed.

\section{RULES GENERATION IN OUR CMRS}

In decision making sub-system of CMRS, the form of dynamic knowledge represents as production rules. In order to generate decision making rules, a set of practical decision data have been got, which is shown in Table.1. In Table.1, Y means that the object will be scheduled to perform the task. W means that it will be regarded as an alternate. $\mathrm{N}$ means that it will not be scheduled. Then KANG's rules generation method [20] can be used.

Table 1. Data for Objects

\begin{tabular}{lllll}
\hline Object & Velocity(VE:m/s) & $\begin{array}{l}\text { Direction Angle(DA: } \\
\text { Degree) }\end{array}$ & $\begin{array}{l}\text { Aim } \\
\text { Distance(AD:m) }\end{array}$ & Perform(PE) \\
\hline 1 & 0.5 & 30 & 1 & $\mathrm{Y}$ \\
\hline 2 & 2 & 110 & 3 & $\mathrm{~N}$ \\
\hline 3 & 1 & 100 & 2 & $\mathrm{Y}$ \\
\hline 4 & 2 & 80 & 2 & $\mathrm{~N}$ \\
\hline 5 & 0.5 & 45 & 3 & $\mathrm{~N}$ \\
\hline 6 & 1 & 90 & 2 & $\mathrm{~W}$
\end{tabular}


1) From the object data, it is clear that VE, $\mathrm{DA}$ and $\mathrm{AD}$ are the condition properties set $\boldsymbol{A}$, while $\mathrm{PE}$ is the decision property set $\boldsymbol{C}$.

2) The number of selected fuzzy interval of VE, DA and AD is 3. They are represented as $\mathrm{L}$ (low-level), $\mathrm{M}$ (middle-level) and $\mathrm{H}$ (high-level).

3) The member function for VE, DA and $A D$ is the same, which is the triangle function depicted in Fig.2.

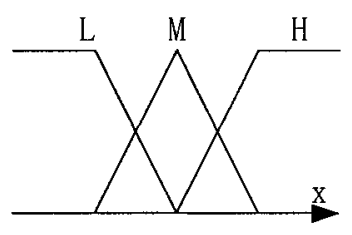

Figure 2. Member Function

4) According to the member function, the properties can be transformed into the following form in Table.2.

Table 2. Data Transformed From Member Functions

\begin{tabular}{lllll}
\hline Object & VE & DA & AD & PE \\
\hline 1 & $0.5 / \mathrm{L}+0.5 / \mathrm{M}$ & $0.67 / \mathrm{L}+0.33 / \mathrm{M}$ & $0.5 / \mathrm{L}+0.5 / \mathrm{M}$ & $\mathrm{Y}$ \\
\hline 2 & $1 / \mathrm{H}$ & $0.67 / \mathrm{M}+0.33 / \mathrm{H}$ & $0.5 / \mathrm{M}+0.5 / \mathrm{H}$ & $\mathrm{N}$ \\
\hline 3 & $1 / \mathrm{M}$ & $0.78 / \mathrm{M}+0.22 / \mathrm{H}$ & $1 / \mathrm{M}$ & $\mathrm{Y}$ \\
\hline 4 & $1 / \mathrm{H}$ & $.11 / \mathrm{L}+0.89 / \mathrm{M}$ & $1 / \mathrm{M}$ & $\mathrm{N}$ \\
\hline 5 & $0.5 / \mathrm{L}+0.5 / \mathrm{M}$ & $0.5 / \mathrm{L}+0.5 / \mathrm{M}$ & $0.5 / \mathrm{M}+0.5 / \mathrm{H}$ & $\mathrm{N}$ \\
\hline 6 & $1 / \mathrm{M}$ & $1 / \mathrm{M}$ & $1 / \mathrm{M}$ & $\mathrm{W}$
\end{tabular}

5) The fuzzy equivalence class matrix can be got from Table.2. It is listed in Table.3.

Table 3. The Fuzzy Equivalence Class Matrix

\begin{tabular}{llllllllll}
\hline & $(\mathrm{L}, \mathrm{L})$ & $(\mathrm{L}, \mathrm{M})$ & $(\mathrm{L}, \mathrm{H})$ & $(\mathrm{M}, \mathrm{L})$ & $(\mathrm{M}, \mathrm{M})$ & $(\mathrm{M}, \mathrm{H})$ & $(\mathrm{H}, \mathrm{L})$ & $(\mathrm{H}, \mathrm{M})$ & $(\mathrm{H}, \mathrm{H})$ \\
\hline $\mathrm{L}$ & $(1)$ & & $(5)$ & $(1)$ & & $(5)$ & & & \\
\hline $\mathrm{M}$ & $(1)$ & & $(5)$ & $(1)$ & $(1,3)$ & $(5)$ & & $(3)$ & \\
\hline $\mathrm{H}$ & & $(4)$ & & & $(2,4)$ & $(2)$ & & $(3)$ & $(2)$
\end{tabular}

6) The decision table (Table. 4) can be got from Table. 2 on the base of the former algorithm.

Table 4. Decision Table

\begin{tabular}{lllll}
\hline Object & VE & DA & AD & PE \\
\hline 1 & L(or $\mathrm{M})$ & L (or $\mathrm{M})$ & $\mathrm{L}($ or $\mathrm{M})$ & $\mathrm{Y}$ \\
\hline 2 & $\mathrm{H}$ & $\mathrm{M}($ or $\mathrm{H})$ & $\mathrm{M}($ or $\mathrm{H})$ & $\mathrm{N}$ \\
\hline 3 & $\mathrm{M}$ & $\mathrm{M}($ or $\mathrm{H})$ & $\mathrm{M}$ & $\mathrm{Y}$ \\
\hline 4 & $\mathrm{H}$ & $\mathrm{L}$ (or $\mathrm{M})$ & $\mathrm{M}$ & $\mathrm{N}$ \\
\hline 5 & $\mathrm{~L}$ (or $\mathrm{M})$ & $\mathrm{L}($ or $\mathrm{M})$ & $\mathrm{M}($ or $\mathrm{H})$ & $\mathrm{N}$
\end{tabular}




\begin{tabular}{lllll}
\hline Object & VE & DA & AD & PE \\
\hline 6 & $\mathrm{M}$ & $\mathrm{M}$ & $\mathrm{M}$ & $\mathrm{W}$
\end{tabular}

Simplify the Table. 4 and the certain rules can be got.

Rule 1: IF $(\mathrm{VE}=\mathrm{H})$ and $(\mathrm{DA}=\mathrm{M})$ and $(\mathrm{AD}=\mathrm{M})$ THEN $\mathrm{N}$

Rule 2: IF $(\mathrm{VE}=\mathrm{H})$ and $(\mathrm{DA}=\mathrm{M})$ and $(\mathrm{AD}=\mathrm{H})$ THEN $\mathrm{N}$

Rule 3: IF $(\mathrm{VE}=\mathrm{L})$ and $(\mathrm{DA}=\mathrm{L})$ and $(\mathrm{AD}=\mathrm{L})$ TEHN $\mathrm{Y}$

Rule 4: IF $(\mathrm{VE}=\mathrm{L})$ and $(\mathrm{DA}=\mathrm{L})$ and $(\mathrm{AD}=\mathrm{M})$ TEHN $\mathrm{Y}$

Rule 5: IF $(\mathrm{VE}=\mathrm{M})$ and $(\mathrm{DA}=\mathrm{L})$ and $(\mathrm{AD}=\mathrm{L})$ TEHN $\mathrm{Y}$

Rule 6: IF $(\mathrm{VE}=\mathrm{M})$ and $(\mathrm{DA}=\mathrm{L})$ and $(\mathrm{AD}=\mathrm{M}) \mathrm{TEHN} \mathrm{Y}$

8) According to the results of step 7), the uncertain decision table (in Table.5.) can be got.

Table 5. Uncertain Decision Table

\begin{tabular}{lllll}
\hline Object & VE & DA & AD & PE \\
\hline 1 & $\mathrm{M}$ & $\mathrm{M}$ & $\mathrm{M}$ & $\mathrm{Y}$ \\
\hline 3 & $\mathrm{M}$ & $\mathrm{M}$ & $\mathrm{M}$ & $\mathrm{Y}$ \\
\hline 6 & $\mathrm{M}$ & $\mathrm{M}$ & $\mathrm{M}$ & $\mathrm{W}$
\end{tabular}

9) The property equivalence class: $\mathrm{K}=\{(\mathrm{M}, \mathrm{M}, \mathrm{M})\}$

The fuzzy equivalence class: $\mathrm{A}^{\prime}(\mathrm{K})=\{(1,3,6)\}$

10) $U /$ ind $(C)=\{(1,3),(2,4,5),(6)\}$

$$
\mathrm{A}^{*}(\mathrm{C})=\{(1,3,6)\}
$$

11) From the formula in KANG's method, the following results can be got. $\mathrm{D}_{1}=\{(1,3),(6)\} ; \mathrm{F}\left(\mathrm{D}_{1}{ }^{1}\right)=0.18 ; \mathrm{F}\left(\mathrm{D}_{1}{ }^{2}\right)=0.17$.

So the uncertain rules can be got.

Rule 7: IF $(\mathrm{VE}=\mathrm{M})$ and $(\mathrm{DA}=\mathrm{M})$ and $(\mathrm{AD}=\mathrm{M})$ THEN $\mathrm{Y}(\mathrm{CF}=0.18)$

Rule 8: IF $(\mathrm{VE}=\mathrm{M})$ and $(\mathrm{DA}=\mathrm{M})$ and $(\mathrm{AD}=\mathrm{M})$ THEN $\mathrm{W}(\mathrm{CF}=0.17)$

12) From the results of Step 7) and 11), the rule set of our decision system can be got.

Rule 1: IF $(\mathrm{VE}=\mathrm{H})$ and $(\mathrm{DA}=\mathrm{M})$ and $(\mathrm{AD}=\mathrm{M})$ THEN N $(\mathrm{CF}=1)$

Rule 2: IF $(\mathrm{VE}=\mathrm{H})$ and $(\mathrm{DA}=\mathrm{M})$ and $(\mathrm{AD}=\mathrm{H})$ THEN N $(\mathrm{CF}=1)$

Rule 3: IF $(\mathrm{VE}=\mathrm{L})$ and $(\mathrm{DA}=\mathrm{L})$ and $(\mathrm{AD}=\mathrm{L}) \mathrm{TEHN} Y \quad(\mathrm{CF}=1)$

Rule 4: IF (VE $=\mathrm{L})$ and $(\mathrm{DA}=\mathrm{L})$ and $(\mathrm{AD}=\mathrm{M})$ TEHN Y $(\mathrm{CF}=1)$

Rule 5: IF $(\mathrm{VE}=\mathrm{M})$ and $(\mathrm{DA}=\mathrm{L})$ and $(\mathrm{AD}=\mathrm{L})$ TEHN Y $(\mathrm{CF}=1)$

Rule 6: IF $(\mathrm{VE}=\mathrm{M})$ and $(\mathrm{DA}=\mathrm{L})$ and $(\mathrm{AD}=\mathrm{M})$ TEHN Y $(\mathrm{CF}=1)$

Rule 7: IF $(\mathrm{VE}=\mathrm{M})$ and $(\mathrm{DA}=\mathrm{M})$ and $(\mathrm{AD}=\mathrm{M})$ THEN $\mathrm{Y} \quad(\mathrm{CF}=0.18)$

Rule 8: $\mathrm{IF}(\mathrm{VE}=\mathrm{M})$ and $(\mathrm{DA}=\mathrm{M})$ and $(\mathrm{AD}=\mathrm{M})$ THEN $\mathrm{W} \quad(\mathrm{CF}=0.17)$

\section{CONCLUSIONS AND FUTURE WORK}

Dynamic knowledge and uncertain rules are usual phenomena in dynamic systems, especially in cooperative multiple robot systems. So, dynamic knowledge extraction is the critical problems to be solved in the modeling 
and analysis of dynamic systems. This paper presents a novel method on the base of KANG's rules generation method [4] to extract dynamic knowledge in our CMRS. The validity of this method has been demonstrated by using it in our cooperative multiple robot system.

In the future, a combined method of extraction, representation and inference method in CMRS will be studied deeply, because the aim of dynamic knowledge is to reason and get the results. Recently, adaptive fuzzy Petri net [10] has been presented. It may be a feasible way to reach our goal.

\section{ACKNOWLEDGEMENTS}

This work is jointly supported by the National Nature Science Foundation for Youth Fund (Grant No: 60405011) and China Postdoctoral Foundation for China Postdoctoral Science Fund (Grant No: 20040350078).

\section{REFERENCES}

1. Pawlak Z. Rough Sets: Theoretical Aspects of Reasoning About Data[M]. Kluwer Academic Publisher, 1994.

2. X.P. Gu S. K. Tso, APPLYING ROUGH-SET CONCEPT TO NEURAL-NETWORKBASED TRANSIENT-STABILITY CLASSIFICATION OF POWER SYSTEMS, Proceedings of the 5th International Conference on Advances in Power System Control, Operation and Management, AF'SCOM 2000, Hong Kong, October 2000, pp.400-404

3. KANG Shengwu1, WANG Yingming, CAI Zhifeng, An Approach to Generating Rules Based on Rough and FSs Theories, Journal of Xiamen University (Natural Science), Vol. 41 No. 2:173-176, Mar: 2002, (See http://www.cd.cnki.net/index.htm)

4. L. A. Zadeh. Fuzzy sets. Information and Control, 8:338-353, 1965.

5. Andrea Bonarini, An Introduction to Learning Fuzzy Classifier Systems, LCS '99, LNAI 1813, pp. 83-104, 2000.

6. Sugeno M, Kang G T. Structure identification of fuzzy model, [J ] . Fuzzy Sets and System, $1988,28: 15-33$.

7. Jang J . ANFIS: Adaptive2network2based fuzzy inference system, [J ] . IEEE Trans. On SMC , $1993,23(3): 665-685$.

8. Yinghua $L$, et al. Nonlinear system input structure identification : two stage fuzzy curves and surfaces[J] ]. IEEE Trans. On SMC part A , 1998, 28(5):678 - 684.

9. Magne $S$, Huns R. Transparent fuzzy modeling using fuzzy clustering and GA' $s[J]$. IEEE Trans. Part C, $1999: 198-202$.

10. X. Li, F. Lara-Rosano, Adaptive fuzzy petri nets for dynamic knowledge representation and inference, Expert Systems with Applications 19 (2000) PERGAMON 235-241 